\title{
Herreros y Cantaores: El trabajo de los metales en la génesis del flamenco
}

\author{
Blacksmiths and Singers: The Iron-Works \\ in the Genesis of Flamenco
}

\author{
Rafael Cáceres Feria \\ y Alberto del Campo Tejedor \\ Universidad Pablo de Olavide, Sevilla
}

\section{RESUMEN}

Entre artistas, aficionados y estudiosos del flamenco existe la generalizada idea de que las herrerías gitanas han constituido, desde antiguo, lugares míticos donde se ha conservado pura la tradición calé; incluso que sería allí donde se habría creado el embrión de lo que después será el flamenco. Por otra parte, a las fraguas gitanas se ha asociado un cante propio y exclusivo: los martinetes, supuestamente ejecutados al ritmo del martilleo sobre el yunque. Este artículo desmonta ambos tópicos, y para ello ahonda antropológicamente en el ambivalente rol y estatus de los gitanos herreros; analiza fuentes históricas que se ocupan del trabajo de los metales entre los gitanos, así como testimonios literarios que recrean escenas de música en las herrerías, y revisa lo que conocemos sobre los martinetes. El texto permite comprender la verdadera dimensión de los gitanos herreros en Andalucía, y en qué medida han jugado estos un papel en la gestación y desarrollo del flamenco.

Palabras clave: Flamenco, Herreros, Martinete, Gitanos, Andalucía.

\section{SUMMARY}

Artists, fans and researchers of flamenco have the widespread idea that gypsy blacksmith's trades have constituted, from ancient, mythical places where gypsy tradition would have remained pure, and that we even could find there the embryo of what later will be known as flamenco. On the other hand, the gypsy blacksmith's trades have been associated to a specific and exclusive style of song, called martinetes, which supposedly were performed with the rhythm of the hammering on the anvil. This article dismantles both topics, studies the ambivalent role and status of gypsy blacksmiths, analyses historical sources that deal with that job between gypsies, takes in consideration testimonies that recreate scenes of music in the iron-works, and reviews what we know about martinetes. The text allows understanding the real dimension of the gypsy blacksmiths in Andalusia, and discovers the role that they have played in gestation and development of flamenco.

Key words: Flamenco, Blacksmiths, Martinete, Gypsies, Andalusia. 


\section{INTRODUCCIÓN}

Manuel Cagancho, Juan Pelao, Pepe Culata, Antonio Mairena, Manuel Agujetas, Santiago Donday, Camarón de la Isla, son solo algunos ejemplos de cantaores flamencos procedentes de familias de gitanos herreros. Y es que este ha sido uno de los oficios más directamente vinculados al flamenco, no solo porque exista un nutrido grupo de artistas que han ejercido esta ocupación, como denotan algunos apodos artísticos ${ }^{1}$, también porque al trabajo en la fragua se ha querido asociar un cante propio, los denominados martinetes. Además, el trabajo de los metales forma parte del universo poético del flamenco, y así sus letras hacen alusión a menudo a un oficio que ha sido santo y seña de la gitanería andaluza ${ }^{2}$.

En ciertos estudios sobre los gitanos andaluces (Luna 1989), algunos autores van más allá, otorgando a las herrerías y a los herreros calés un papel crucial en la génesis del flamenco. Según esta visión, las fraguas serían los espacios donde los gitanos habrían conservado y reproducido sus tradiciones ancestrales, lejos de la contaminación de la música andaluza. Y así los martinetes, considerados los cantes de herrería por antonomasia, constituirían uno de los sones más puros y genuinamente gitanos.

Ciertamente la relación entre fragua y flamenco no carece de lógica, teniendo en cuenta que los gitanos han trabajado como herreros desde su llegada a la Península en el siglo XV. Sin embargo, nos parecen muy discutibles las conclusiones que se han querido derivar de esta correlación, frecuentemente demasiado simplificadora. A menudo, la flamencología ha rodeado el mundo de la herrería de un aura romántica que ha servido para justificar un origen exclusivamente gitano de la música flamenca. Así, intentaremos desmontar aquí tanto la idea de que los gitanos herreros habrían sido una suerte de enigmáticos custodios de la tradición calé, como la interpretación de los martinetes como cantes de herrería. Si ambas visiones nos parecen erróneas y mitificadas, entonces, ¿cuál es el vínculo entre fragua y flamenco?, ¿de dónde derivan estos clichés? Creemos que las respuestas merecen ser indagadas ahondando en el significado económico, social y simbólico que ha tenido el oficio de herrero, un trabajo considerado marginal durante siglos (como tantas otras labores manuales), pero que, por su utilidad, sirvió para que los gitanos pudieran ser percibidos como provechosos, permitiéndoles una relativa sedentarización, cierto grado de integración

\footnotetext{
${ }^{1}$ Cagancho es el mote familiar de una dinastía de fragüeros trianeros dedicados al cante y a los toros. Es creencia entre los aficionados al flamenco que el nombre le vendría de los ganchos de hierro que fabricaban. Cantaor fue Tío Juan Cagancho y su hijo Manuel Cagancho. Molina Fajardo (1974: 64) cita entre los artistas granadinos del siglo XIX al guitarrista Juan el Calderero y al bailaor Manuel el Calderero, apodados así, probablemente, por la profesión que ejercían. Herrero fue también el cantaor malagueño Manolillo el Herraor (1900-1980) y el cantaor payo de Las Cabezas de San Juan, Fernando Sánchez Moreno, conocido artísticamente como Fernando el Herrero (1877-1941).

${ }^{2}$ A la puertecita de la fragua / no me vengas a buscar. / Con el fango a las ró́llas / y las enagüitas remangás. // Madre mía de mi alma, / padre mío, qué vergüenza / que se enteren los gitanos / que tengo la fragua en venta. // Yunque, fragua y martillo / rompen los metales. / El juramento que yo a ti te he hecho / no lo rompe nadie. // Por dinero no lo hagas. / Llévame a una herrería / y échame un hierro a la cara. // Los carbones de la fragua / dicen a mi corazón: / lo que más duele en el mundo / es quemarse de pasión.
} 
y, sobre todo, la asimilación de la cultura andaluza (incluyendo sus patrones estéticos y musicales), elementos fundamentales para comprender el surgimiento del flamenco.

En este artículo analizamos la relación entre flamenco y herrería partiendo de fuentes documentales de muy diversa naturaleza. Por una parte, tenemos en cuenta documentación histórica y trabajos historiográficos que se ocupan del mundo laboral gitano desde su llegada a la Península hasta el siglo XIX, para determinar qué peso y consideración ha tenido la profesión de herrero en la sociedad andaluza. Nos interesa conocer cuáles fueron las peculiaridades de este oficio en relación a otras ocupaciones asociadas al mundo gitano, y si estas particularidades guardan alguna vinculación con el surgimiento del flamenco. Por otra parte, abordamos la relación histórica de los herreros gitanos con la música; sin desdeñar los testimonios literarios (comedias, pliegos de cordel, tonadillas, zarzuelas, sainetes, novelas) que recrean el mundo de las fraguas y otros contextos gitanos, nos detenemos especialmente en diversa documentación —desde trabajos teóricos de flamencólogos o biografías de artistasque abordan los martinetes, para determinar cuál es la relación entre este palo flamenco y el trabajo de los metales.

\section{LOS GITANOS HERREROS}

A pesar de las variaciones en función de la época histórica y el contexto, los gitanos se han concentrado en torno a unos mismos oficios en todo el continente europeo, empleándose como vendedores ambulantes, chalanes, esquiladores, músicos o en la fabricación de objetos metálicos. Este último trabajo resulta especialmente interesante, entre otras razones porque, como sugiere Torcuato Pérez de Guzmán (1982: 32), no se ajusta al estereotipo de un pueblo escasamente laborioso, cuando no ocioso, vago. No obstante, el vagabundeo y los trabajos del metal se han asociado a los gitanos desde antiguo. Una Pragmática de los Reyes Católicos, promulgada en 1499, obliga a "egipcianos y caldereros extranjeros" a que "tomen asiento en los lugares y sirvan a los señores que les den lo que hubiera menester y no vaguen juntos por reinos" (apud Mayo 1870: 24).

Dentro del trabajo de los metales, algunos gitanos europeos se especializaron en la calderería o la fabricación de joyas, mientras que en el caso español, la herrería se afianzó progresivamente como su especialidad metalúrgica. En general, cuando las fuentes antiguas mencionan a herreros gitanos, se refieren a los que fabrican objetos de metal de escaso valor, como clavos, alcayatas o herraduras, y por otra parte a los que tienen como profesión reparar aperos de labranza, útiles de molinos, carros y otros objetos domésticos. No se trata del único trabajo metalúrgico que ejercían los gitanos españoles; también se emplearon como caldereros, hojalateros o paragüeros, labores con un marcado carácter ambulante, consideradas entre los escalafones más bajos de la metalurgia.

Un secular estereotipo explicaba la afición de los gitanos a estos oficios por su inclinación a fabricar útiles con fines delictivos. Sancho de Moncada considera en 1619 que los gitanos "son gente ociosa, vagabunda, inútil a los Reynos, sin comercio, ocupación, ni oficio alguno; y si alguno tiene es hacer ganzúas, y garabatos para su pro- 
fesión" (Moncada 1746: 131). Otro tanto repite Juan Quiñones de Benavente en su Discurso contra los gitanos $(1631)^{3}$, tópico que recrearía muchas veces la literatura del Siglo de Oró ${ }^{4}$.

Sin embargo, las razones de esa larga tradición forjadora tenían que ver, sobre todo, con su carácter itinerante y autosuficiente. Un grabado del pintor flamenco Joris Hoefnagel, que viajó por España en la segunda mitad del siglo XVI, presenta a dos herreros trabajando al aire libre, a las afueras de Marchena (Sevilla), con un instrumental mínimo consistente en varios martillos, algunos fuelles y dos pequeños yunques. Efectivamente los fragüeros ${ }^{5}$ se desplazaban de pueblo en pueblo, reparando y vendiendo piezas. Muchas de estas cuadrillas estaban formadas por gitanos, como recrea Jerónimo de Alcalá, en la segunda parte de Alonso, mozo de muchos amos (1626).

Por otra parte, la vinculación de los gitanos a la herrería derivaba de un imprescindible y autosuficiente abastecimiento, especialmente por las necesidades que tenían como tratantes de bestias. Hay que tener en cuenta que el herrador no solo se ocupaba de las herraduras; durante siglos constituyó una especie de albéitar de segundo orden. Así, en unas ordenanzas de Badajoz del siglo XVII se especifica que el cometido de los herradores es "preparar cualquier género de herradura, echarlas a cualquier cabalgadura, curar sus enfermedades y sangrarlas" (Marcos Álvarez 1998: 14). Por la misma época, en Plaza universal de todas ciencias y artes (1615), Cristóbal Suárez de Figueroa escribe despectivamente cómo los herradores participan en el trato de ganados, vinculándolos a gentes de poco fiar, como los gitanos ${ }^{6}$.

De la misma manera, otros oficios tradicionalmente gitanos — desde el de trasquilador hasta el de ventero- se explican por esta ligazón entre el trato de bestias y una vida itinerante, de feria en feria. La legislación antigitana, promulgada a partir del siglo XV, censura muchas veces que los gitanos se dediquen a algunos de estos trabajos, abogando por su sedentarización, a través de la labranza de la tierra, pero los gitanos siguieron desempeñando estos oficios a través de los siglos ${ }^{7}$. Aún en 1788,

\footnotetext{
${ }^{3}$ Quiñones de Benavente los compara con los moriscos y los considera aún peor al no trabajar la tierra: "Si en algo se ocupan, es en hacer barrenas, por ser una especie de ganzúas, y aun por disimularlas, las muchas que entre las barrenas hacen" (apud Grande 1999: 539).

4 El propio Cervantes da crédito a esta opinión. En El coloquio de los perros, Berganza, uno de los canes protagonistas, menciona - al describir su estancia con un grupo de gitanos cerca de Granada-, que estos se emplean "por dar color a su ociosidad, en labrar cosas de hierro; haciendo instrumentos con que facilitan sus hurtos; y así, los verás siempre traer a vender por las calles tenazas, barrenas, martillos, y ellas, trébedes y badiles" (Cervantes 2007, II: 348). En Pedro de Urdemalas (1615), Cervantes vuelve a mencionar el trabajo de los herreros como uno de los rasgos típicos de los gitanos, asociados también al vagabundeo, el engaño y el robo.

5 Aunque el DRAE no recoge este término, es de uso habitual, al menos en muchos lugares de Andalucía. En la Alpujarra, aún se conoce quiénes pertenecen a las familias de fragüeros de Cádiar y Ugíjar.

6 "Suelen sobre todo los Herradores entremeterse con los Potros, asistiendo en sus ventas, y las de mulas, y asnos, por entender comúnmente destos animales; aunque muchas veces son peores que Gitanos, haziendo ventas y trueques con engaño y malicia, gastando grande almacen de palabras superfluas" (Suárez de Figueroa 1615: fol. 204v.).

7 Fue necesario un reiterado esfuerzo legislativo para que algunos gitanos abandonaran sus oficios tradicionales y acogieran el cultivo de la tierra. A partir del siglo XVIII encontramos con cierta frecuencia pequeños y medianos campesinos gitanos que se encuentran integrados en poblaciones andaluzas (Zoido 2009; Sánchez 1977).
} 
afirmaba Antonio de Capmany: "Herrería y trasquila, las carnicerías y las posadas, ¿no corren a manos de mulatos y gitanos?" (Capmany 1788: 197).

\section{UN OFICIO VIL: EL ESTATUS DE HERRERO}

El trabajo del metal tuvo siempre una consideración ambivalente, cuando no misteriosa, según demuestra Mircea Eliade (2009). La capacidad de transformar la materia vinculaba la metalurgia a la alquimia, incluso a la hechicería. Durante siglos, y en diferentes culturas, la herrería ha supuesto una especie de conocimiento secreto que muy pocos controlaban, de ahí que los herreros alcanzaran en muchos lugares un estatus singular, nada inequívoco: mientras que en algunas culturas gozaban de un gran prestigio, en otras provocaban resquemor, cuando no un enorme rechazo, por su oscurantismo.

En España, los gitanos forjadores sufrieron siempre el recelo de la población mayoritaria. Un criterio útil para evaluar la categoría de un trabajo es comprobar los grupos sociales que lo ejercen. Aquellas tareas ligadas a minorías étnicas marginales —negros, mulatos, gitanos, moriscos - tenían también, salvo excepciones, el más bajo estatus. En el caso de los herreros, sabemos que no fue un trabajo despreciado por musulmanes, ni judíos. Posteriormente, moriscos y en general los conversos siguieron desarrollándolo. En las ordenanzas de la ciudad de Granada de 1552 que regulan los distintos oficios, se distingue entre la herrería cristiana y la morisca, mencionándose como objetos característicos de la herrería musulmana las axorcas morunas y los clavos moriscos (Caro Baroja 2000: 96). Cuando los moriscos fueron deportados, muchos de ellos no pudieron tener acceso a la tierra, por lo que no fue infrecuente que se dedicaran a la arriería y a múltiples actividades artesanales, entre ellas las metalúrgicas, lo que constatan reiteradamente los ya numerosos estudios locales y generales sobre los moriscos (Domínguez Ortiz y Vicent 1978: 111; Boeglin 2010: 160; Santamaría 1983: 10). De hecho, pocos años después de la expulsión, fray Jaime Bleda especifica que los moriscos que trabajaban el metal eran sobre todo los herradores "por el grande amor que tenían a sus respetados machos, y para hazer hoces, almaradas, achuelas; armas que tenían siempre a mano" (Zayas 2006: 181).

Así pues, hay una relación lógica, tanto entre la herrería y los gitanos tratantes de bestias, como entre los herradores y los arrieros moriscos. Unos y otros interactuaron, máxime cuando —como mantienen Julio Caro Baroja (1980: 116), Domínguez Ortiz y Bernard Vicent (1978: 264-268) — muchos de los moriscos encontraron cobijo en bandas de vagabundos y gitanos, especialmente en las ciudades andaluzas. Vinculado a moriscos y conversos, gitanos y mulatos, no extraña que el oficio de herrero quedara en gran medida estigmatizado, y más aún el de herrador. A su naturaleza de oficio manual, mecánico, en oposición al trabajo liberal (único que podían desempeñar la nobleza y los hijosdalgo), se le unían las duras condiciones laborales; con calor, exigente ejercicio, y el consustancial ruido, que provocaba no pocas quejas entre los vecinos donde se instalaban, incluso aunque fuera transitoriamente. Por otra parte, el menosprecio a las artes mecánicas hay que ponerlo en relación, también, con al aseo (Guillamón 1982: 55). El propio Campomanes, en la época en que los ilustrados intentaban erradicar la secular desconsideración hacia la artesanía y la industria, insisti- 
ría en ese aspecto: "Los herreros suelen caer en la misma falta, trayendo la cara tiznada de los carbones: de ahí resultan los apodos de chisperos; las pullas, y el que se escondan, por no poder sufrirlas muchos menestrales" (Rodríguez Campomanes 1774: 174). No podemos obviar que el concepto de pureza en oposición al de contaminación, tal y como sugiere la antropóloga Mary Douglas (1991), se relaciona con el sistema simbólico de una sociedad. La suciedad está vinculada tanto a la higiene como al respeto de las normas y convenciones culturales. La pureza sirve para marcar la frontera entre lo lícito y lo ilícito, lo sagrado y lo profano, y en la Península, entre la limpieza de sangre castellana y la mezcolanza de los trabajadores viles, siempre sospechosos de ser castellanos nuevos y, por lo tanto, estigmatizados.

Finalmente, el carácter ambulante, inestable, así como la vinculación con las bestias y las ferias, contribuyeron sin duda a su bajo estatus, a diferencia de la estima de la que gozaba la labranza de la tierra. Los trabajos de obra menuda, desarrollados especialmente por gitanos y otros morenos, al margen de los gremios ${ }^{8}$, eran los más desconsiderados. Esto es singularmente evidente en Andalucía. Como señala Gonzalo Anes (1975), en la franja norte no todos los oficios mecánicos eran rechazados, al considerarse compatibles con la hidalguía. En cambio, en el sur, una parte de la población se oponía a ejercer ciertos oficios envilecedores, lo que justifica, en parte, la presencia en el siglo XVIII de un elevado número de extranjeros desempeñando diversas tareas en ciudades como Cádiz o Sevilla (Anes 1975: 319-320). De la misma manera es otra de las razones que explica el gran número de gitanos forjadores en Andalucía. Más aún: al sur de Despeñaperros, la identificación del oficio de herrero o esquilador con la población gitana fue tan asumida, que el desempeño de dichos trabajos fue uno de los criterios utilizados por las autoridades para definir quién pertenecía y quién no a esa etnia9.

Sin embargo, a diferencia de otras labores propias de gitanos - trajinante, ventero o esquilador-, el trabajo de los metales alcanzó un estatus más ambiguo, incluso respetable en muchos casos, dada su utilidad. De hecho, puede afirmarse que los herreros, a pesar de los prejuicios existentes, constituían probablemente el grupo de gitanos más aceptado, incluso en los momentos en que la ley les impedía desempe-

\footnotetext{
${ }^{8}$ Para Domínguez Ortiz (1990: 388-389), en un país con tan bajo aprecio por los oficios manuales había que buscar mecanismos para hacer distinciones en estos trabajos. Ahí radica una de las razones de la creación de cofradías profesionales con reglamentaciones propias que filtraban a los trabajadores que podían entrar. Algunos gremios prohibían expresamente la utilización de mano de obra mulata, negra, gitana o esclava; incluso se censuraba a aprendices expósitos. Además, establecían normas precisas en cuanto a la indumentaria y a los símbolos que los distinguían. Sabemos por las ordenanzas de muchos de estos gremios de herreros, que era habitual exigir limpieza de sangre y que los gitanos eran normalmente proscritos. Esto generó no pocos conflictos, incluso pleitos ante la justicia, que en muchos casos se saldaron a favor de los gitanos, como en un litigio de los herreros payos de Málaga contra sus homónimos gitanos, a finales del siglo XVII, cuya resolución será favorable a estos últimos, gracias, en parte, al apoyo de la Hermandad de Viñeros, cuyos miembros llevaban a reparar a los gitanos sus útiles de labranza, y al gremio de herradores, que argumentarán que eran los gitanos quienes les abastecían de herraduras y clavos (Bejarano 1975).

9 Por eso durante la Gran Redada de 1749 se apresaron algunos payos, por la mera razón de ser fragüeros. Alfonso Lazo (1974: 12) cita un ejemplo de una familia de herreros payos de Jerez de la Frontera que, en 1751, será incluida en la lista de gitanos que debían abandonar la ciudad.
} 
ñar su oficio. Hay testimonios suficientes para asegurar que muchas ciudades y pueblos se debatieron entre el recelo, cuando no la explícita repulsa hacia el avecinamiento de gitanos herreros, y su aceptación a regañadientes, dado el imprescindible servicio que prestaban ${ }^{10}$. Así, desde finales del siglo XVI y principios del XVII se fueron formando auténticas comunidades gitanas en multitud de poblaciones andaluzas, en torno a familias de herreros y herradores ${ }^{11}$. Con el tiempo, si los gitanos andaluces vinieron a identificarse como el summum prototípico del gitano español, el herrero se convirtió en muchos casos en arquetipo del gitano andaluz, sedentario e integrado (dado que trataban continuamente con payos, sus principales clientes), aunque manteniendo peculiaridades de su etnia ${ }^{12}$.

\section{LOS HERREROS Y LA MÚSICA}

La asociación entre música y herrería no es fortuita. En la India, forjador y músico aparecen vinculados en algunas castas (Clebert 1965: 29). En unas eruditas páginas, Mircea Eliade (2009: 91-92) rastrea en la mitología una clara relación entre el arte de trabajar el hierro y la música. ¿Es que los gitanos herreros españoles tendían a ocuparse también como músicos? Existen, desde luego, numerosos testimonios que sugieren que los gitanos se ganaban la vida con la música, casi desde su entrada en la Península Ibérica. Así, por ejemplo, en el Auto de las gitanas de Gil Vicente, representado en 1525 aproximadamente, en el transcurso de un sarao cortesano, ya aparecen gitanas y gitanos cantando y danzando, mientras las primeras piden limosna y echan la buenaventura. A lo largo de los siglos XVI y XVII es habitual encontrar gitanos en las procesiones del Corpus Christi, en mascaradas y otros espectáculos callejeros ${ }^{13}$. Las comedias y novelas recrean con cierta frecuencia estos bailes y danzas gitaniles ${ }^{14}$. No es fácil, empero, identificar una tradición musical propia y des-

\footnotetext{
${ }^{10}$ En Jerez aparece registrado un grupo de gitanos herradores de bestias y de vendedores ambulantes en 1524 (De la Plata 2001: 8). En 1589, el ayuntamiento jerezano concede los primeros permisos para que varios herreros calés puedan ejercer su oficio en la ciudad ( $\mathrm{ibid}$. 50). Significativo es también el caso de un tal Nicolás Maldonado que, en 1588, se traslada desde el Marquesado de Cenete a La Zubia, en la vega granadina, donde solicita avecinarse. Será admitido con la única condición de no acoger en su casa a gitanos que no fuesen familiares directos, y, como afirma el Cabildo, "para que los vecinos pagándole su trabajo puedan calzar sus rejas y azadas y hacer las cosas necesarias a labradores" (Martín Quirantes 1995: 87). Semejantes episodios se seguirán repitiendo durante siglos.

${ }^{11}$ En el siglo XVII encontramos en Jerez a un grupo de gitanos caldereros asentados en la calle Larga, y otros gitanos herreros avecinados en el barrio de San Miguel (De la Plata 2001: 63, 82).

${ }^{12}$ Utilizamos este concepto no en su acepción decimonónica de raza sino en el sentido que le ha dado la antropología social a partir de la segunda mitad del siglo XX, como un colectivo cuyos miembros comparten ciertos rasgos culturales fruto de su historia, se identifican entre sí y son identificados por otros grupos (Barth 1976: 11).

13 Por ejemplo, en Toledo fueron representadas danzas de gitanas para dar la bienvenida a la reina Isabel de Valois, en 1560 (Esses 1992, I: 474).

${ }^{14}$ Cervantes describe en Pedro de Urdemalas cómo unos gitanos ejecutan una de sus danzas para el rey (Cervantes 2003, II: 807 y sig.), mientras en La elección de los alcaldes de Daganzo convencen al mayordomo encargado de la fiesta del Corpus Christi para que cuente con ellos (Cervantes 2003, II: 922).
} 
gajada de la de sus contemporáneos no gitanos. En los testimonios literarios que nos han llegado, los gitanos ejecutan romances, coplas, villancicos, seguidillas, y bailan zarabandas, villanos, chaconas o el polvico, todos considerados licenciosos en su época. Aunque ninguno de estos géneros es exclusivamente gitano, los dramaturgos vinculan los personajes gitanos a bailes caracterizados por su sensualidad y desparpajo, de la misma manera que los harán acompañar con el tiempo de elementos coreográficos específicos como las castañetas o las palmas ${ }^{15}$.

La flamencología ha considerado durante mucho tiempo que los gitanos habrían tenido una singularidad musical ocultada, siglo tras siglo, en la oscuridad de las herrerías. No hay dudas con respecto a dos hechos: la importancia de los gitanos herreros en Andalucía y la importancia de los gitanos en el flamenco ${ }^{16}$, como también es claro que ambos - herrería y flamenco - estuvieron vinculados a otras clases bajas, morenos de todo tipo, pero también lumpen urbano en general. Cuestión diferente es atribuir a las herrerías un privilegiado lugar como espacios para el cante y la música, tanto en su ejecución, como en su aprendizaje y conservación, como si allí se hubiera salvaguardado una supuesta "prístina pureza gitana"

Así, pues, dos son los interrogantes que hay que despejar: ¿Se cantaba en las herrerías? ¿Son los martinetes los primitivos cantes de las fraguas gitanas andaluzas, como se ha venido aceptando un tanto acríticamente? La vinculación entre cante y trabajo manual es virtualmente un hecho cultural universal. Más específicamente, un presunto y tópico carácter festivo y cantarín de los andaluces, fuesen campesinos o artesanos, no pasó desapercibido para los extranjeros que desde mediados del XVII viajaban a la Península Ibérica al acecho de lo exótico, buscando un pasado que en Europa había sido borrado por una naciente modernidad e industrialización. Se asombraban de que en España se cantara y se bailara a todas horas, incluso, mientras se trabajaba, y muy especialmente en las provincias del $\operatorname{sur}^{17}$. Entre los siglos XVIII y XIX, el humilde trabajador andaluz — campesino, arriero, barbero, vendedor ambulante-, que componía, cantaba, incluso improvisaba coplas de repente, se convirtió en un arquetipo folclórico, múltiples veces recreado por los escritores costumbristas, como Benito Más y Prat ${ }^{18}$.

Sin embargo, la herrería apenas aparece entre los contextos propicios para la música y el canto. En Problemas de la filosofía natural, acompañados de consideraciones morales (1652), Juan de Zabaleta, cronista de Felipe IV, se pregunta: "¿Por qué ordinariamente los que hacen alguna cosa de trabajo corporal cantan?" (Zabaleta 1667: 56). Y responde que la música hace olvidar la pena (ibid.: 56-57). Zabaleta mencio-

\footnotetext{
${ }^{15}$ Así, en la mojiganga de La Gitanada (ca. 1670), los gitanos bailan al son de estas coplas: "Las gitanas y gitanos / zapatean con las manos; / y sin que el compás se pierda, / con la derecha y la izquierda" (Cotarelo 2000, I: CCL).

16 Aunque no faltan autores (Lavaur 2008; Steingress 2006) que le restan importancia o interpretan de forma muy diferente el papel de los gitanos en la génesis del flamenco.

17 El italiano Baretti, por ejemplo, que estuvo de viaje por España en 1760, se hacía eco de una idea que se había ido forjando desde el Siglo de Oro: los andaluces, junto con los manchegos y portugueses, serían los más apegados a los bailes y cantos populares.

18 Sobre "la copla gitana, o el cantar andaluz" escribe el folclorista de Écija: "La vena del pueblo es inagotable [...] canta a todas horas, en toda ocasión y en todo tiempo; cuando trabaja y cuando descansa, en el taller y en la campiña, en la barricada y en el porche del templo" (Más y Prat 1923: 101-102).
} 
na a los herreros, y habla metafóricamente de las consonancias que arrojan los golpes del martillo, música hecha con las manos, en vez de con la garganta. El ritmo del martillo es lo que alivia la fatiga del herrero, pero no el canto, incompatible con el ruido del golpear de los martillos. De hecho una de las acepciones de 'herrería' es la de "ruido acompañado de confusión y desorden, como el que se hace cuando algunos riñen o se acuchillan" (DRAE). En múltiples obras de diferentes épocas se habla de "montar una herrería" para expresar la idea de armar jaleo.

Con todo, no faltan testimonios literarios sobre herreros cantarines. Uno de los primeros lo encontramos en la tragicomedia Fragua de amor (1524), de Gil Vicente. En una de las escenas aparece una bucólica herrería donde los forjadores cantan plácidas serranas mientras trabajan (Vicente 1843: 339). Se trata de un cuadro con reminiscencias mitológicas, al tratarse de una obra de carácter alegórico. Durante el Siglo de Oro, son numerosísimas las referencias a barberos que cantan folías o pasacalles (Del Campo y Cáceres 2013a; 2013b), soldados, mozos de mulas o arrieros improvisadores de versos (Del Campo 2004; 2006), castañeras que pregonan su mercancía, y otros vendedores y artesanos que canturrean alguna copla mientras trabajan. Sin embargo, las referencias literarias a la música en la fragua brillan por su ausencia. Algo más frecuentes son en el siglo XVIII, pero escasamente relevantes. En la obra de Faustino Núñez, Guía comentada de música y baile preflamencos (1750-1808), donde se analizan más de tres mil piezas musicales de distinto tipo (tonadillas escénicas, sainetes, zarzuelas), hay solo un puñado de menciones a manifestaciones musicales en herrerías. Y eso a pesar de que el autor, conocedor de la mítica importancia de los herreros en el flamenco, dedica a este asunto una especial atención. Nuestras largas pesquisas en todo tipo de obras de los siglos XVIII y XIX —comedias, pliegos de cordel, tonadillas, sainetes, novelas - han arrojado el mismo resultado: las menciones a fraguas como espacios musicales y a forjadores que cantan son no solo escasas, sino con un marcado carácter literario, nada realistas. No podemos olvidar que la fragua es, por su seducción simbólica y estética, un lugar propicio para convertirlo en espacio escénico. Daremos algunos ejemplos: De 1775 es la estrafalaria comedia de autor desconocido, Brancanelo el herrero, de corte mágico y ambientada en Rusia. Comienza con una escena en una fragua donde varios herreros, que golpean con sus martillos la bigornia, cantan a coro al compás de las herramientas, alternándose con un herrero que canta en solitario ${ }^{19}$. La imagen es tan romántica, como inverosímil. Solo un puñado de testimonios son algo más realistas. En el sainete de 1792, El tío Bigornia, aparecen dos herreros que cantan mientras faenan. La didascalia reza: "zaguán de herrador... banquillo con bigornia, y en él Faco y Bastián trabajando y cantando" (Álvarez Barrientos 1987: 33). En la comedia de mediados del XVIII, El asombro de Salamanca, también se presenta a unos caldereros cantando ${ }^{20}$. En la tonadilla La trapera, un italiano y un herrero (1765), este último canta alegremente a golpe de un martillo: "Arda la fragua, prosiga el incendio, y al compás del martillo se ablande

\footnotetext{
${ }^{19}$ El coro canta: "Tan, tan, tin, tin, tin, / tin, tin, tin, tin, tin, tin, / que nuestros afanes / se alivian así" y el solitario cantor entona sublimemente: “¡Oh, cuánto en la fragua / de amor, más feliz / que los corazones, / quema sin herir" (Brancanelo el herrero 1987: 57-58).

20 "Siempre machacando, / siempre trabajar, / siempre alborotando / a la vecindad. / Tin, tin, tin, / tan, tan tan..." (Álvarez Barrientos 1987: 33).
} 
el hierro, tin, tin tintin tin, tin..." (Núñez 2008: 80). En otra tonadilla, de 1778, Los chascos de Pantalón, de nuevo un herrero interpreta una canción acompañándose de su martillo: "A golpe de martillo del tarantantán, se gana el dinero para manducar, tintirintín" (ibid.: 80).

Si en las herrerías se cantaba, no parece que se ejecutaran tonadas emparentadas con los que después serán conocidos como martinetes flamencos. Estos tienen un carácter triste y se cantan individualmente, mientras los ejemplos tonadilleros y sainetescos son alegres (allegro, andantino) y asiduamente aparecen interpretados a coro (a tres, a cuatro, a cinco), sin duda más por el efectismo demandado en los teatros, que por algún ánimo de plasmar la realidad de un modo fidedigno. En la tonadilla El relojero (1763) el canto que se interpreta es una jota: "y la jotita linda te cantaré... (Martillo a compás)" (Núñez 2008: 81). Tampoco parecen muy tristes los sones de los martillos del sainete de Blas de Laserna, El astrólogo fingido (1789): "trabaje la aguja, machaque el martillito, que todo sea broma, fiesta y regocijo" (ibid.: 81). Un ambiente festivo es también el que encontramos en la herrería de Los Payos hechizados (1809), del mismo autor, donde incluso se baila al compás del martillo: "Al son sonecito de mi martillo, alma morena ven y bailarás" (ibid.: 81). Algo más verosímil parece el contexto de la herrería del sainete de Ramón de la Cruz, El calderero y vecindad (1822). El célebre sainetero presenta el conflicto entre los caldereros y sus vecinos que, entre otras cosas, se quejan del jaleo que arman tanto por el ruido, como por sus canciones (De la Cruz 1843, I: 51).

También encontramos gitanos fragüeros en algunos sainetes, especialmente del gaditano Juan Ignacio González del Castillo. En el titulado La boda del Nuevo Mun$d o$, de finales del XVIII, el protagonista es Pechuga, un gitano herrero (González del Castillo 1846). El mundo de la herrería gitana de Triana es el tema central de la comedia de Luis Mejías, Los gitanos de la Caba o ya cayó el Ministerio (1865), donde se presenta una curiosa visión de las fraguas gitanas; una rebelión o huelga de los herreros solicitando mejoras laborales.

La alusión a herreros en zarzuelas y tonadillas escénicas no es casual, como tampoco la de herreros específicamente gitanos. En estos géneros se solían introducir personajes que desempeñaban oficios populares y que permitían reproducir escenas con rasgos costumbristas. Para identificarlos, los personajes aparecían con los elementos propios de su labor (Romero Ferrer 1993: 67). El herrero cantando al compás del martillo resultaría espacialmente sugerente, de la misma manera que la herrería con sus yunques y mazos es un espacio teatralmente atractivo. Las posibilidades escénicas de las fraguas quedan constatadas asimismo en los desfiles, mascaradas y procesiones en los que participaban los distintos gremios en la celebración del Corpus Christi o so pretexto de la conmemoración de algún evento o efeméride. Los fragüeros solían aparecer golpeando el yunque con sus martillos, simulando que trabajaban el hierro y, en ocasiones, cantando y bailando (Torre Molina 2003: 288, 353, 349). En estos espectáculos callejeros, los forjadores gitanos no participaban con el gremio de herreros, al no estar integrados en estas asociaciones profesionales. Las denominadas danzas de gitanos aparecen al margen de los trabajadores del metal, y no se acompañan jamás con martillos sino con panderos, castañetas y otros instrumentos considerados como típicos de gitanos.

Es sintomático en primer lugar que, a diferencia de lo que ocurre con los barbe- 
ros y otros oficios, no hayamos encontrado entre los siglos XV y XVIII ninguna referencia histórica y descriptiva (al margen de lo literario) sobre herreros músicos y cantores. Pero más significativa es aún la ausencia, hasta el siglo XIX, de referencias sobre gitanos cantando en la fragua, siempre literarias por otra parte. El acto segundo de la famosísima zarzuela El Tío Caniyitas o El Nuevo Mundo de Cádiz (1849), está ambientado en eel interior de una fragua con todos sus útiles correspondientes, en medio dos o tres yunques sobre los cuales trabajan varios herreros" (Sanz 1849: 26). Al ritmo de sus martillos, los fragüeros cantan a coro mientras faenan. Como de costumbre, ni el tipo de cante, ni las letras guardan relación alguna con el flamenco. Asimismo, en la ópera de Verdi Il Trovatore (1853), en el acto segundo, en un campamento, un coro de gitanos canta mientras se escucha el golpear de los martillos sobre el yunque. El libreto de esta ópera está basado en la obra El trovador (1836) del chiclanero Antonio García Gutiérrez, pero adaptado por el italiano Salvatore Cammarano. En el drama original no consta esta escena. Se trata, pues, de un recurso escénico añadido para crear exotismo y ofrecer una ambientación tópicamente gitana y española. El acto primero de la Vida Breve (1913) de Manuel de Falla se desarrolla en el Albaicín granadino, en el interior de una herrería donde los gitanos cantan a coro mientras trabajan. Pero lo que cantan no es flamenco, pues lo hacen primero a dúo y posteriormente todos los hombres de la fragua, a coro. En la zarzuela cómica El querer de una gitana (1914), en el cuadro primero ambientado en el Albaicín granadino, aparece igualmente una casa con una fragua donde un herrador trabaja en su yunque. Un nutrido grupo de gitanos y gitanas cantan al compás del repique del martillo sobre el yunque: «iTrin, Trin, Trin! ¡Trin, Trin, Trin! / ¡Trin, Trin, Trin! ¡Trin, Trin, Tran! / ¡Dale, dale al martillo / contra los yunques / de la herrería! / ¡Trin, Trin, Trin...!" (Fernández Palomero 1914: 9).

Un elemento común a estas escenas de herreros que cantan mientras trabajan, es el recurso de incluir el doble de los martillos sobre las bigornias, que se intenta reproducir mediante sonidos onomatopéyicos del tipo: "Tan, tan, tin, tin, tin" que aparece en Brancanelo el herrero, el "tin, tin, tin" de la comedia Asombro de Salamanca, o el "trin, trin, tran" de El querer de una gitana. Ciertamente el yunque y el martillo se han utilizado como instrumentos musicales en diversos tipos de música. Y es que el sonido penetrante y misterioso al chocar el hierro debió fascinar desde el descubrimiento de la metalurgia. Según testimonio de alguno de sus discípulos, Pitágoras se habría interesado por los fundamentos matemáticos de la música al pasar por la puerta de una herrería y escuchar el sonido armónico que producía el golpear de un martillo sobre el yunque. Comprobando que los sonidos variaban según el tamaño del martillo, descubrió la relación entre los sonidos musicales y los números enteros (Bergua 1995: 100-101). En su Diccionario técnico de la música, Felipe Pedrell (1897) incluye la bigornia como instrumento de percusión utilizado en algunas obras por músicos como Hálevy o Verdi (Pedrell 2009: 54). También en El Anillo de los Nibelungos de Wagner, se escuchan dieciocho yunques golpeados con martillos. Igualmente lo utiliza Joseph Strauss en su polca op. 269: La fiesta de fuego. ¿Pero pueden aducirse estos ejemplos como recreaciones de lo que realmente ocurría en las fraguas?

Incluso aunque se pensara en la remota posibilidad de que en las herrerías se cantara, pese al ruido y las duras condiciones de trabajo, ¿por qué entonces no encontramos ni una sola referencia histórica, empírica?, ¿por qué no aparecen precisa- 
mente gitanos fragüeros cantando y bailando, como sí es frecuente en otros oficios desde al menos el siglo XV? Además, ¿cómo explicar que en las recreaciones literario-musicales, escasas y poco realistas, no se aluda a ningún tipo específico de cante de herrería, y mucho menos los autores inventen canciones que podríamos emparentar con lo que hoy se considera el palo típicamente de herreros: los martinetes? Si tenemos en cuenta la tradición musical gitana y su afición al cante, y que el herrero constituyó, efectivamente, uno de sus oficios predilectos, es lógico pensar que las forjas gitanas fueran lugares donde cotidianamente se pudiera escuchar música. Incluso, que en ocasiones se usase el martillo como instrumento de percusión, lo mismo que se han utilizado muchos otros objetos domésticos. Hay que tener en cuenta que, con frecuencia, las herrerías constituían a la vez viviendas o estaban próximas a las mismas. Por eso no extraña que Augustus Hare describa, en 1871, el ambiente del Sacromonte granadino, donde en el aire flotaban las canciones gitanas (Hare 2010: 165). Pero nada de esto sugiere un contexto donde los gitanos habrían salvaguardado arcaicas formas musicales que de repente, en el siglo XIX, aparecen conocidas como martinetes. Más bien, las herrerías gitanas constituirían lugares de interacción entre morenos y payos durante siglos. Así, si el oficio de herrero facilitó la vinculación de los gitanos con lo que después sería conocido como flamenco, fue porque como trabajo marginal, itinerante y desprestigiado, permitió la imbricación con otros grupos subalternos andaluces, incluyendo moriscos y negros. La herrería puso a los gitanos en contacto con las capas populares andaluzas, no gitanas, muy especialmente cuando se avecinaron en muchos pueblos y ciudades de Sevilla, Cádiz o Málaga (Mandly 2010).

Solo un apunte histórico permitiría refrendar las extendidas ideas entre aficionados y estudiosos del flamenco en torno a las herrerías gitanas como núcleos de gestación del flamenco. En la biografía que de Silverio Franconetti nos ofrece Demófilo, el folclorista relata que el cantaor de Morón "aficionado al canto desde sus primeros años, empezó muy pronto a desesperar a sus padres con sus frecuentes rabonas a la sastrería y sus continuas visitas a una fragua próxima a su casa donde pasaba las horas muertas embebecido en oír cantar a los gitanos" (Machado y Álvarez 1998: 205). Este parece el único y aislado testimonio que podría utilizarse para argumentar la existencia de supuestos cantes de fragua. Pero lo cierto es que, dado que se trata de una única mención, lo único que parece sugerir es que los gitanos cantaban, también, al parecer, - podríamos decir incluso- en el contexto de una fragua, pero no que estuviera generalizado. En el repertorio de Silverio que recoge Demófilo encontramos los cantes propios de gitanos en ese momento: polos, cañas, seguiriyas y, también, serranas. Pero nada se dice de los martinetes. Si Silverio aprendió a cantar en una fragua, con la devoción que sentía por los cantes típicamente gitanos, ¿cómo no incluyó los martinetes en su repertorio?

\section{AL COMPÁS DEL MARTILLO: LOS MARTINETES}

No solo aficionados, cantaores y flamencólogos ven en el martinete un cante fragüero, surgido al compás de los golpes de los martillos sobre el hierro de las fraguas gitanas. Incluso un autor tan suspicaz con el flamenco como Caro Baroja, que 
puso en cuarentena todas las teorías tradicionales sobre esta música, aceptaba que "el cante ha nacido - como se sabe- al son de los golpes del martillo, al ruido del martinete (Caro Baroja 1980: 120). Las características del martinete —especialmente la ausencia de acompañamiento musical y su ritmo monótono- suelen explicarse esencialmente por este origen (Luna 2010: 45). La idea no presenta demasiadas fisuras tampoco entre folcloristas, historiadores y otros estudiosos, aunque no resiste, en nuestra opinión, un análisis riguroso.

Veamos: la primera referencia a este palo la encontramos en Machado y Álvarez, quien se refiere a ellos en la introducción a sus Cantes flamencos (1881). El padre de los poetas Machado incluye los martinetes entre los cantes flamencos y afirma que se denominan, también, carceleras; "llamados de ambos modos, según unos, porque se cantan al son de martillos en las fraguas, y según otros, por ser propios de presidiarios" (Machado y Álvarez 1998: 20). Ni el propio Demófilo tenía claro en su época las causas de dicha denominación, mucho menos el origen de un cante poco conocido, apenas interpretado por los cantaores profesionales (ibid.: 20), lo que explica que sintiera una especial fascinación por él y decidiera dedicarle un espacio notable. El hecho de que no formara parte de los repertorios habituales de los cafés cantantes; el estar vinculado a espacios de la vida gitana; así como sus propias características musicales (monótono, melancólico y con profusión de palabras en caló), le llevan a conjeturar sobre la posibilidad de que se trate de uno de los cantes más antiguos, de los más "puramente" gitanos y de los que mejor reflejarían el espíritu de este pueblo, en una época en que los folcloristas buscan el Volksgeist en costumbres y formas artísticas celosamente guardadas por un pueblo que existió más en su imaginario que en la realidad. El martinete sería un cante en apariencia sencillo, pero muy difícil de interpretar: "Según nos informó un aficionado bastante inteligente, que nos acompañaba, la música de los martinetes, que es acompasada, sin grandes subidas ni bajadas, se presta poco a ser aprendida" (ibid.: 20).

Machado y Álvarez no va más allá de esta referencia a los martinetes como cantes de herrería. En cambio, al analizar sus letras se refiere en todo momento al martinete como cante de presidiarios (ibid.: 20). Al compararlos con las recopilaciones de coplas de cárceles de los italianos Giuseppe Pitré y Apolo Lumini, Demófilo recalca la naturaleza penitenciaria de los martinetes (ibid.: 174). ¿Pudo influir el carácter marginal de esta música para que no formara parte, en un principio, de los repertorios de los cantaores profesionales? Quizás fuese este el motivo por el que había que "acudir a gente, por lo común recelosa y desconfiada, para adquirir algunos datos y recoger algunas letras", como afirma Machado y Álvarez (ibid.: 174).

En todo caso, es altamente significativo que, a pesar de la presunta antigüedad del palo, no se encuentren referencias al martinete como cante con anterioridad a Demófilo, y que en las recreaciones literario-musicales tampoco hallemos alusiones explícitas a sones de esas características en las herrerías. Por el contrario, aunque escasos, hay datos que evidencian la existencia de cantes en las cárceles. El médico sevillano Cristóbal de Chaves relata que cantar era uno de los entretenimientos de los presos en la cárcel de Sevilla, a finales del siglo XVI. Allí, reclusos y reclusas se comunicaban con canciones que acompañaban haciendo "el sonecillo en los grillos con un cuchillo o en la reja" (Chaves 1983: 23), cuando no había guitarra. Años después, la mujer del alcaide de la cárcel de Toro le cuenta a George Borrow que en 
esa prisión se toca la guitarra y se canta (Borrow 2002: 255). Una de las pocas referencias a esta música, anterior a la obra de Machado y Álvarez, es la que nos ofrece Davillier, que visitó la cárcel de Sevilla donde escuchó cantar a presos y centinelas. Afirma el barón que entre los cantes que se lanzaban al aire en prisión, estaban los romances y otros que se denominaban carceleras $^{21}$ (Davillier 2009: 310).

Cree Gerhard Steingress $(2007 ; 2006)$ que tonás, carceleras y martinetes son cantes que derivan de las primitivas saetas andaluzas, anteriores al flamenco. En Andalucía, los presos interpretarían esas saetas desde la cárcel, al paso de las procesiones de semana santa. Dichos cantes tendrían un claro aire oriental al estar basados en la liturgia cristiana y el canto bizantino. Sustituyendo el contenido religioso por temas profanos, se expresarían los lamentos de los cautivos.

Machado y Álvarez atestigua que en su época se escuchaban pocos martinetes. Sin embargo, los grandes intérpretes de este palo surgen, justamente, en el último cuarto del siglo XIX, con la aparición de los cafés cantantes. Entre ellos destacan Juan Pelao, Manuel Cagancho o el Señor Manuel Molina. Es llamativo que a partir de esos momentos apenas se utilice el término 'carcelera', y se reemplace por el de 'martinete'. Parece que, ni en sus momentos de auge, a finales del XIX y principios del XX, fue este cante en exceso popular. Falla tendrá la misma sensación que Machado y Álvarez, medio siglo después: se encontraba ante un son en decadencia y, por eso, lo incluyó dentro del repertorio que debían ejecutar los cantaores en el Concurso de Cante Jondo de Granada de 1922. Tanto su temática como el estilo romancesco de su ejecución, podrían explicar su alejamiento de los escenarios. Su carácter minoritario y su escasa difusión han servido, en todo caso, para alentar el mito de un cante íntimo, casi olvidado, procedente del oscuro mundo privado de los hogares y fraguas gitanos. Como hemos recalcado, la idea es repetida frecuentemente, aunque sin evidencias: frente a los sones interpretados en los cafés-cantantes, los gitanos poseerían una serie de cantes reservados, que no "comercializaban", y que tendrían para deleite propio (Lefranc 2001: 75).

Es habitual recurrir a un testimonio de Fernando el de Triana (1986: 55), en relación al cantaor de martinetes Juan Pelao, para justificar esta teoría. Este artista, herrero trianero, relata que en una ocasión se encontraba reunido en un bar, en privado, para cantar con otros gitanos. Un general aficionado al cante tuvo que escucharlo desde la puerta al no consentírsele la entrada. Al parecer, en un arranque de orgullo, el cantaor se negó a que entraran payos o que le pagaran por su cante (Triana 1986: 53). Sin embargo, lo que demuestra esta anécdota no es la existencia de cantes ínti-

\footnotetext{
${ }^{21}$ Parece que alcanzar la nota más alta constituía uno de los aspectos que más se valoraba en ese cante. En la cárcel de Sevilla, Davillier escucha a un preso —el más famoso de ese lugar-, del que describe su peculiar manera de cantar: "Con unas modulaciones, de un ritmo muy difícil de coger, cantándolas con la boca cerrada. Después su voz, sin dejar de ser un poco nasal, se hizo cada vez más sonora, y llegó al fin a las notas más altas. Comenzó entonces un canto profundamente melancólico y de una gran originalidad [...]. El motivo de estas canciones es casi siempre el mismo, y siempre también la melodía está impregnada del salvajismo y la tristeza que produce en estos hombres indisciplinados la privación de libertad" (Davillier 2009: 311). El testimonio está cargado de romanticismo, pero sugiere veracidad. Lo más relevante de la descripción del francés es que confirma que en esos momentos este cante había cristalizado como género diferenciado, al mismo nivel de consolidación que las playeras o las malagueñas.
} 
mos, exclusivos y ocultos, pues la reunión tuvo lugar en un espacio público (un bar). Por otra parte, suele omitirse que Juan Pelao acabó accediendo a recibir dinero. Más bien el episodio es significativo de un hecho conocido entre los aficionados al flamenco: la negativa de muchos cantaores a amoldarse a las exigencias del "mercado" ${ }^{22}$, anteponiendo su libertad a la hora de elegir dónde y ante quién cantar. Las herrerías gitanas no solo no fueron lugares herméticos, sino que algunas se convirtieron en espacios escénicos para "turistas". A mediados del XIX, el Cujón, guitarrista, cantaor y herrero granadino, instaló en su herrería una sala donde actuaban los artistas gitanos del Sacromonte, convirtiéndose en la primera zambra de Granada (Molina Fajardo 1974: 97). Como en muchas de las recreaciones literarias y teatrales analizadas con anterioridad, sin duda se trataba aquí de crear un producto al gusto de un público ávido de exotismo.

Ricardo Molina y Antonio Mairena defienden que los martinetes no son más que una nueva denominación para las tonás con temas de herrería: "Las que desarrollaban el tema dramático de los gitanos encarcelados llamáronse 'carceleras' y probablemente calificaron de martinetes a las que acostumbraban a cantar en las herrerías" (Molina y Mairena 1979: 163). Estos autores insisten en la modernidad de este cante: "Primitivamente se hablaba de tonás; luego el término fue sustituido por carcelera y modernamente por el de 'martinete', pero carceleras y martinetes no son sino modalidades de la toná" (ibid.: 164). Hay que recordar que Antonio Mairena procede de una familia de fragüeros, y que él mismo trabajó en su infancia de herrero en la fragua de su padre, en Mairena del Alcor (Sevilla). Antonio Mairena sabía perfectamente que era imposible cantar una toná al compás de un martillo. Seguramente jamás lo presenció. Por eso rechazaba que los cantaores recurrieran a interpretar este palo al son de un martillo, por romántico y exótico que fuera para el público (ibid.: 162). Nos parece este un indicio imposible de obviar. Y es poco verosímil, y en todo caso carece de fundamento, intentar salvar el escollo, como hace Ángel Álvarez Caballero (2007: 57), vinculando estos cantes a los momentos de descanso en la fragua. Es posible que entonces se cantara. Pero como en cualquier otro contexto gitano.

¿Hay alguna evidencia contrastada, entonces, para ligar martinetes y herrerías? La conexión más obvia parecería la propia denominación de estos cantes. Gran parte de la flamencología da por hecho que el nombre se refiere a los martillos de los forjadores, lo que parece harto discutible. 'Martinete' es vocablo que con anterioridad al siglo XVIII solamente lo encontramos en relación a un ave o a la pieza que golpea las cuerdas de un clavicordio. En el Tesoro de la lengua castellana o española de Covarrubias (1611) se menciona 'martinete' como el badajo de una campana. Tampoco aparece la acepción herrera en el Diccionario de Autoridades (1726). Solo posteriormente se vincula esta palabra con las herrerías. En realidad se trata de un galicismo, y si bien puede significar 'martillo de herrería' no se aplica, nunca o casi nunca, a los martillos de los que se sirven los herreros en las pequeñas fraguas. Por el contrario, el martinete se refiere a los grandes martillos hidráulicos de las ferrerías preindustriales que empiezan a generalizarse en el siglo XVIII y, por extensión, a estos

\footnotetext{
${ }^{22}$ Algunos artistas, como Tomás Pavón, llevaron este punto hasta el extremo de renunciar, a pesar de sus cualidades, a convertirse en profesionales del cante. El flamenco como profesión es analizado por Cristina Cruces (2003: 238-245).
} 
establecimientos industriales. Finalmente designa a una máquina empleada para clavar estacas.

En ningún caso se encuentra el vocablo ligado a las fraguas gitanas. Allí se suele hablar de 'mazo', 'martillo' o 'martillo pilón'. Tampoco aparece la palabra en ninguno de los múltiples diccionarios de lengua gitana que se escriben en el siglo XIX, donde se menciona currandó (Tineo 1900: 31), la palabra gitana que recogen casi todos los diccionarios caló para denominar al martillo. Ni la hallamos en ninguna recopilación de coplas populares, con esa acepción. En el Cancionero de Lafuente Alcántara y en el de Rodríguez Marín se habla del martinete de Heredia, pero este se refiere a la fábrica de hierro malagueña (Lafuente Alcántara 1861: 74; Rodríguez Marín 1995: 162).

¿Por qué se iba a emplear, para denominar un presunto cante gitano, un término que estos no utilizaban en absoluto? ¿Se trata de una denominación popular que no aparece por escrito? Merece la pena que nos detengamos en alguna de las acepciones, muy especialmente la que designa una máquina que consta de un gran mazo, usado para clavar estacas. Pierre Lefranc sugiere que el martinete es un cante que pudo surgir durante el cautiverio de los gitanos, a mediados del siglo XVIII, en el arsenal de La Carraca, en San Fernando (Cádiz). En este establecimiento, y durante el tiempo que muchos gitanos permanecieron prisioneros entre 1749 y 1765 , se construye un muelle, varios astilleros y un dique. Sabemos que participaron en estas labores esclavos musulmanes y presos gitanos. Al tratarse de un terreno fangoso, parece que fue necesario clavar estacas en el barro para lo que se utilizaron, tal y como documenta Lefranc, varios martinetes movidos por reos. Algunas letras de tonás recogidas por Machado y Álvarez reflejarían, según el estudioso francés, estas circunstancias de trabajo en el agua ${ }^{23}$. Lefranc argumenta que este cante tendría influencias de los sones de los esclavos musulmanes que movían esos martinetes, en paralelismo a los lamentos de galera que menciona el Bachiller Revoltoso en el Libro de la Gitanería de Triana, de mediados del siglo XVIII ${ }^{24}$. Finalmente, después del cautiverio, habrían pasado al anonimato ${ }^{25}$. Se trata de una hipótesis ingeniosa y atractiva, aunque de difícil demostración. Algunos indicios son además débiles: a pesar de que algunas de estas letras hagan referencia a esos acontecimientos, en otras se mencionan hechos muy diferentes y, a veces, anteriores a la prisión en La Carraca, como el cautiverio en las minas de Almadén de los gitanitos de El Puerto ${ }^{26}$.

Parece confirmarse que martinetes, carceleras y deblas son un mismo cante, variantes temáticas y melódicas de un palo general denominado toná. Antonio Machado, en cambio, creía que carceleras y martinetes constituían el mismo palo, y los di-

${ }^{23}$ Lefranc, Pierre, "Otro suplemento martinetero", Triste y Azul, http://www.tristeyazul.com/ hinvestigacion/Martinete_Pierre_Lefranc.html (consultado 8-11-2012).

${ }^{24}$ Lefranc, Pierre, "Entremés sobre el aparato llamado martinete", Triste y Azul, http:// www.tristeyazul.com/hinvestigacion/Entremes_martinete_lefranc.html (consultado 8-11-2012).

${ }^{25}$ Lefranc, Pierre, "La génesis del martinete II", jondoweb.com, http://www.jondoweb.com/contenido-la-genesis-de-martinete-ii-747.html (consultado 8-11-2012).

26 "Los gitanitos del Puerto / fueron los más desgraciados / que a las minas de Azogue / se los llevan sentenciados". La toná en cuestión se hace eco del apresamiento de un grupo de gitanos del Puerto de Santa María que fueron conducidos a las minas de Almadén en 1745 (Zoido Naranjo 2009: 106). 
ferenciaba de deblas y tonás, si bien encontraba entre ellos elementos comunes como eran su antigüedad (los consideraba cantes arcaicos en desuso) y el carecer de acompañamiento musical (Machado y Álvarez 1998: 187). Además observó que, aun estructurados en cuartetas, estas solían estar conectadas unas con otras, y los cantaores tendían a interpretarlas seguidas como " $\operatorname{corridos}^{27}$ de tres, cuatro y cinco coplas que vienen a formar, por decirlo así, pequeños trovos en los que se conservan hechos particulares que aún viven en la memoria de los cantaores" (ibid.: 173). Incluso cuando se cantaban una o varias cuartetas sueltas, parece que algunas "formaron también parte de un trovo, cuyo principal objeto es lamentarse de los trabajos y desgracias que sufren los pobres presos en los establecimientos penales" (ibid.: 173). Efectivamente, en su análisis de las letras de martinetes y carceleras, Demófilo pudo comprobar que el tema más recurrente eran las duras condiciones de vida de los gitanos, principalmente en las cárceles.

Autores como García Matos creían que las tonás no eran más que "estilizaciones de cancioncillas populares diversas que unos u otros gitanos sabrían de haberlas oído en los medios folklóricos de tal o cual región o provincia peninsular" (García Matos 1987: 80). Se apoyaba en el hecho de que en multitud de poblaciones de España se denomina tonás o tonadas a cualquier canto tradicional (ibid.: 80). En la actualidad, hay cierta unanimidad en aceptar que una parte de estos cantes provienen de romances fragmentados (García Gómez 1993: 197-198). La raíz romancística de las tonás explicaría que estos cantes presenten, pese a su temática triste — común a otros cantes flamencos-, claras diferencias con otros palos. Así, frente a la más lírica seguiriya, las tonás son narrativas. Por otra parte no expresan la angustia existencial o amorosa, como es común en las seguiriyas, sino la queja por las condiciones de vida. La peculiaridad temática de las tonás respondería a un proceso de selección con respecto a los romances, escogiendo las partes que harían alusión a cárceles o persecuciones.

No resulta extraña la influencia del romancero en la música gitana. Casi desde su llegada a la Península Ibérica, los gitanos debieron familiarizarse con este género, y lo incorporarían a su repertorio pues era lo que demandaba el público, tal y como recrea Cervantes en La Gitanilla (Cervantes 2007: 72). Un indicio de la familiaridad de los gitanos con los romances es que no ha sido del todo infrecuente que algunos calés tomaran nombres de personajes del romancero. Así, ya a finales del siglo XVI, encontramos un gitano de Triana con el nombre de Bernardo del Carpio; y otro del mismo nombre en Sanlúcar de Barrameda (Suárez Ávila 1994: 246-247) y Jerez (De la Plata 2001: 62).

A partir de finales del siglo XVII, los romances comenzaron a perder importancia, especialmente en las ciudades. Con el romanticismo, el romancero volverá a cobrar protagonismo, y así, por su carácter arcaico, tanto en la temática como en la forma de ser interpretados, fue uno de los cantos que interesó a los extranjeros que en el siglo XIX recorrían los caminos de España en busca de pintoresquismo. La literatura de viajes está llena de referencias a estos cantos y a la fascinación que ejercían estos monótonos romances, entonados unas veces por ciegos rezadores, otras por rudos arrieros.

\footnotetext{
${ }^{27}$ Según Luis Suárez Ávila (2006), corridos, corridas o carrerillas son formas de denominar a los romances por los gitanos bajoandaluces. Esta denominación aparece ya en la literatura del Siglo de Oro.
} 
Es probable que los romances que desde el siglo XVI vienen ejecutando los gitanos no fueran muy distintos a los que cantaban los payos. Pero en su interpretación debieron imprimirle un sello propio, tal y como hicieron con otros cantes. En $\mathrm{La}$ Gitanilla de Cervantes, Preciosa canta un romance con "sus sonajas y al tono correntío y loquesco" (Cervantes 2007, I: 67). El calificativo 'loquesco' viene a subrayar el carácter libre y salvaje, con el que al parecer los gitanos adornaban su música, algo que será reiterado múltiples veces en los siglos siguientes. Los gitanos ejecutarían los romances de manera diferenciada a como lo hacían los ciegos que pululaban por toda España, y es posible que en la célebre descripción que hace Estébanez Calderón de un baile en Triana, la principal diferencia entre el romance que canta el Planeta y los que interpretan los ciegos, sean los adornos vocales que el cantaor añade ${ }^{28}$. Si en la actualidad se considera el romance flamenco como un cante a palo seco, en el pasado los gitanos no lo entonarían necesariamente sin acompañamiento musical, si hemos de dar crédito a las recreaciones literarias que nos han llegado (Estébanez Calderón 1960: 116). La diferencia principal entre los romances tradicionales y los que dieron lugar a las tonás, es que en estos últimos los protagonistas son los propios gitanos y se narran acontecimientos concretos acaecidos a este pueblo.

\section{CONCLUSIONES}

Hemos atestiguado que las referencias a herreros y herrerías son escasas en los martinetes. Además, muchas de las letras que se centran en esta temática son relativamente nuevas, surgidas con posterioridad a que se divulgara la idea de que los martinetes fueran cantes de fragua. Del análisis expuesto creemos que, así como se constata históricamente el papel jugado por los gitanos andaluces en las herrerías, no es posible confirmar que los martinetes sean cantes asociados directamente a ese oficio, ni que las fraguas fueran un contexto particularmente apropiado para el cante, mucho menos para algún tipo de música exclusiva y oculta. No hay ninguna evidencia fidedigna que indique que se cantasen al son del martillo en las fraguas. Por otra parte queda claro que los martinetes son cantes que estructural y temáticamente están emparentados con los romances.

Sin embargo, que los martinetes no puedan ser considerados cantes de herrería, ni que esos espacios fuesen el sacrosanto lugar de la pureza gitana, no prejuzga que los forjadores y fraguas no hayan ocupado un lugar relevante en el mundo flamenco. Como acertadamente ha escrito Pérez de Guzmán (1982: 106), "durante decenios cante y forja fueron inseparables aunque no todos los herreros cantaran ni todos los cantaores fueran herreros". Como gitanos, son depositarios de una larga tradición que, aunque siempre en hibridación con las músicas peninsulares de cada época, salvaguardaron ciertas especificidades. Su pronta sedentarización en las poblaciones andaluzas, su articulación dentro del tejido social andaluz y su fuerte aculturación, los hace herederos de las tradiciones musicales de Andalucía, gitanas y no gitanas. Dicha con-

\footnotetext{
${ }^{28}$ Cuando uno de los asistentes a la fiesta de Triana le pide al Planeta el romance de Gerineldo, este dice: "el romance de Gerineldos lo sé de coro y ya que no con discante y gorjeos, al menos se lo iré relatando al son y compás del pasitrote que llevamos" (Estébanez Calderón 1960: 120).
} 
fluencia nos parece fundamental para entender qué es el flamenco, como no hay que menospreciar que el trabajo de los metales contribuyera a aglutinar los elementos morenos y marginales de la cultura andaluza.

No todos los gitanos se integraron de igual forma en las poblaciones del sur. De hecho, fueron los trabajadores de los metales los que tuvieron menos obstáculos para avecinarse y ser aceptados, ya que prestaban un imprescindible servicio a la población. A pesar de que los herreros no gitanos tendieron a excluirles de sus gremios, no cabe duda que el de fragüero constituyó una de las escasas maneras de ser gitano razonablemente aceptadas en Andalucía. En un momento en que se estaba gestando la sedentarización de la población calé, en ciertos espacios urbanos confluyeron gitanos nómadas o seminómadas procedentes de diferentes áreas geográficas, los cuales convivirán con los estratos más bajos de la población andaluza que desempeñaban con frecuencia idénticos trabajos. Estos barrios jugarán un papel decisivo en el proceso de transformación y aculturación de la población gitana, que fue progresiva y no supuso la total desaparición de su cultura. Triana, barrio fragüero por antonomasia, será uno de los contextos donde se gestaría lo que hoy conocemos como flamenco. Y los gitanos fragüeros jugaron su papel. Prácticamente ninguno de los que participaron en estos espectáculos, cantando y bailando para foráneos, hasta mediados del XIX, eran profesionales de la música. Cantaores y bailaores eran los mismos que machacaban el hierro o soplaban los fuelles en las fraguas. Ciertamente, estos herreros, que también se dedicaban a la música y el cante, se diferenciaban considerablemente de los que recorrieron los caminos peninsulares en siglos anteriores. Ellos hablaban con acento andaluz, vestían como andaluces y cantaban coplas andaluzas. A diferencia de Demófilo, que ponía el acento en la dicotomía entre lo gitano y lo andaluz, Hugo Schuchardt, por la misma época, supo apreciar claramente el carácter andaluz de estos gitanos (Schuchardt 1990: 35), es decir, las vinculaciones culturales comunes de las clases populares del sur, fueran gitanos o payos.

De entre estas familias gitanas surgirán cantaores flamencos, no tanto debido a su condición de herreros sino, sobre todo, por ser gitanos asentados. Y así, de las dinastías de fragüeros saldrán no solo cantaores, sino también otros oficios vinculados a los gitanos de ciertos arrabales: toreros, por ejemplo. Las familias de herreros no son naturalmente las únicas canteras del arte flamenco. Otros oficios, ocupados en gran parte por gitanos, facilitaron este mismo proceso de hibridación, sedentarización y aculturación; es el caso de carniceros y trabajadores de mataderos que, junto con los fragüeros, conforman los grupos profesionales más representativos en el flamenco.

Como otros trabajos, los forjadores aunaron dos elementos que se presentan a veces como antagónicos, pero que han sido los dos vectores de este arte mestizo que es el flamenco: la tradición gitana (en hibridación con otras culturas morenas) y la asimilación de los patrones culturales no gitanos de las clases populares andaluzas. Siglos atrás, en las herrerías ya se habrían mezclado primero con moriscos y otras clases subalternas, a la par que el oficio de herrero era identificado como típico de gitanos. Y sin embargo, dada su utilidad, que afianzó la sedentarización de núcleos de gitanos, se convirtió en uno de los trabajos que posibilitó cierta aceptación. No hay que olvidar que, más allá de su importancia económica y social, en el mundo de la herrería nunca se disipó su fuerte carga simbólica, habida cuenta de que, entre todos los oficios de gitanos, este era el que más se percibía con un ambivalente halo de 
sospecha, misterio y fascinación. El duro esfuerzo que exige el trabajo en la fragua contrasta con la imagen del gitano indolente, y otorga al trabajador de los metales un estatus superior. No es casual, por lo tanto, que cuando el romanticismo ensalce la figura del gitano, se elija al herrero como prototipo calé, por contraste con el esquilador, el tratante y otros arquetipos devaluados, que sí se prestaban más al retrato vil, cómico y degradante.

¿Qué cante podía representar mejor a los gitanos en el siglo XIX que un son nacido supuestamente en la oscuridad de la fragua, al compás del martilleo sobre el yunque? Es probable que el martinete no sea más que un cante tradicional interpretado por gitanos - la toná o la carcelera-, con una cobertura romántica que lo convertiría con el tiempo en pieza ideal, no solo para los escenarios sino también para hacer cabalgar la imaginación, ávida de exotismo mitificador. Así, pocos autores se abstienen de recrear, al referirse a un cantaor gitano de familia herrera, su infancia machacando el hierro mientras canta martinetes o escucha cantar a su padre con el tintineo del hierro de fondo. Y eso, pese a la evidencia de que multitud de cantaores, fragüeros de oficio o herencia, nunca escucharon entonar martinetes a sus progenitores en la herrería. Como ejemplo, baste citar a Antonio Mairena, hijo de un herrero de Mairena del Alcor:

Tenía mi padre una herrería en Mairena, y tuve que ayudarle en el trabajo, a pesar de mis cortos años. Por necesidad económica de la familia, yo, que era el mayor de mis hermanos, sólo pude ir a la escuela durante unos tres años, y en ese corto espacio de tiempo apenas si asistía un día sí y dos o tres no, por mor del trabajo en la herrería (Mairena 1976: 48-49).

No tuvo Mairena artistas flamencos en la familia que le sirvieran de claros referentes, solo algunos familiares que cantaban en fiestas. La desahogada posición económica de los Mairena posibilitó que se organizaran en la herrería y en casa reuniones donde acudían importantes artistas, y sabemos que el padre solía visitar junto a su hijos los locales de la Alameda en los que se cantaba flamenco, tal y como relata en sus memorias (Mairena 1976: 48-49). Pese al tópico, Mairena nunca cantó en la herrería:

Recuerdo la primera vez que salí cantando en presencia de otras personas. Fue en una fiesta gitana familiar. Hasta entonces ni mis padres me habían oído. Esto fue en el año 1920 y en una fiesta que se organizó con motivo de la estancia del bailaor Faíco en Mairena (Mairena 1976: 51).

¿A qué aludir entre estudiosos y aficionados del flamenco, reiteradamente, a la fragua familiar cuando se habla sobre Mairena, como si fuera allí donde se hospedara alguna oscura esencia?

\section{BIBLIOGRAFÍA CITADA}

Alcalá, J. de. 2002. "Alonso. Mozo de muchos amos II", en Sevilla, F. (ed.), La novela picaresca española. Madrid: Editorial Castalia.

Álvarez Barrientos, J. 1987. "Introducción”, en Brancanelo el herrero: 7-57. Roma: Bulzoni Editore.

Álvarez Caballero, Á. 2007. "Los cantes primitivos o a palo seco". La Nueva Alboreá. Revista de la Agencia Andaluza para el Desarrollo del Flamenco 3: 54-55. 
Anes, G. 1975. El Antiguo Régimen: los Borbones. Madrid: Alianza.

Autoridades, Diccionario de la Lengua Castellana, llamado de... 1990 [1726-1739]. 3 vols. Madrid: Gredos.

Bachiller Revoltoso. 1995. Libro de la gitanería de Triana de los años 1740 a 1750 . Sevilla: Junta Municipal de Triana.

Baretti, G. 2005. Viaje de Londres a Génova a través de Inglaterra, Portugal, España y Francia. Barcelona: Reino de Redonda.

Barth, F. 1976 Los grupos étnicos y sus fronteras. México: FCE.

Bejarano Robles, F. 1975. "Los gitanos de Málaga”. Jábega 11: 6-12.

Bergua, J. 1995. Pitágoras. Madrid: Clásicos Bergua.

Boeglin, M. 2010. Entre la Cruz y el Corán. Los Moriscos en Sevilla (1570-1613). Sevilla: Ayuntamiento de Sevilla.

Borrow, G. 2002. La Biblia en España. Madrid: Alianza.

Brancanelo el herrero. 1987. Edición de J. Álvarez Barrientos. Roma: Bulzoni Editore.

Cammarano, S.; Verdi, Il trovatore, http://www.orfeoed.com/opera/libretos/trovatore_lib.pdf.

Capmany, A. de. 1788. "Discurso político económico, sobre la influencia de los gremios en el Estado, en las costumbres populares, en las artes, y en los mismos artesanos". Semanario erudito, que comprehende varias obras inéditas, críticas, morales, instructivas, políticas, históricas, satíricas, y jocosas, de nuestros mejores autores antiguos y modernos. Valladares de Sotomayor, A. Tomo X. Madrid: Don Blas Roman.

Caro Baroja, J. 1980. Temas castizos. Madrid: Istmo.

Caro Baroja, J. 2000. Los moriscos del Reino de Granada. Madrid: Istmo.

Cervantes, M. de. 2003. Obras completas. 2 vols. Madrid: Aguilar.

Cervantes, M. de. 2007. Novelas ejemplares. 2 vols. Madrid: Cátedra.

Clebert, J. P. 1965. Los gitanos. Barcelona: Aymá.

Cotarelo y Mori, E. 2000. Colección de Entremeses, Loas, Bailes, Jácaras y Mojigangas. 2 vols. Estudio preliminar e índices de J. L. Suárez García y A. Madroñal. Granada: Editorial de la Universidad de Granada.

Covarrubias Orozco, S. de. 1994. Tesoro de la lengua castellana o española. Madrid: Castalia.

Cruces, C. 2003. Antropología y flamenco. Más allá de la música (II). Sevilla: Signatura.

Chaves, C. de. 1988. Relación de la cárcel de Sevilla. Madrid: Clásicos El Árbol.

Davillier, C. 2009. Viaje por Andalucía. Sevilla: Renacimiento.

De la Cruz, R. 1843. Sainetes. Vol. I. Madrid: Librería Europea de Hidalgo.

De la Plata, J. 2001. Los gitanos de Jerez. Jerez: Cátedra de Flamencología y Estudios Folklóricos Andaluces.

Del Campo, A. 2004. "Trovadores de repente. La improvisación poética en el Siglo de Oro". eHumanista 4.

Del Campo, A. 2006. Trovadores de repente. Una etnografía de la tradición burlesca en los improvisadores de la Alpujarra. Salamanca: Miletnio, Diputación de Salamanca.

Del Campo, A y Cáceres, R. 2013a. "Tocar a lo barbero. La guitarra, la música popular y el barbero en el siglo XVII". Boletín de Literatura oral 3: 9-47.

Del Campo, A. y Cáceres, R. 2013b. Historia cultural del flamenco (1546-1910). El barbero y la guitarra. Sevilla: Almuzara.

Domínguez Ortiz, A. 1990. Sociedad y Estado en el siglo XVIII español. Barcelona: Ariel.

Domínguez Ortiz, A. y Bernard, V. 1978. Historia de los moriscos. Vida y tragedia de una minoría. Madrid: Editorial Revista de Occidente.

Douglas, M. 1991. Pureza y peligro: un análisis de los conceptos de contaminación y tabú. Madrid: Siglo XXI.

Eliade, M. 2009. Herreros y alquimistas. Madrid: Alianza.

Esses, M. 1992-1994. Dance and Instrumental Diferencias in Spain during the 17th and early 18th centuries. 3 vols. Nueva York: Pendragon Press.

Estébanez Calderón, S. 1960. "Un baile en Triana”, en Escenas andaluzas. Madrid: Espasa Calpe.

Fernández Palomero, M. 1914. El querer de una gitana. Zarzuela cómica en un acto. Madrid: Sociedad de Autores Españoles. 
Fernández-Shaw, C. y Falla, M. de. 2012. La vida breve, http://lazarzuela.webcindario.com/RES/ r_lavidabreve.htm. (Consultado 10-10-2012).

García Gómez, G. 1993. Cante flamenco, cante minero. Una interpretación sociocultural. Barcelona: Anthropos.

García Gutiérrez, A. 1839. El trovador. Zaragoza: Librería de Juan Repilando.

García Matos, M. 1987. Sobre el flamenco. Estudios y notas. Madrid: Cinterco.

González del Castillo, J. 1846. "La boda del Nuevo Mundo", en Sainetes. Cádiz: Imprenta, Librería y litografía de la Revista Médica.

Grande, F. 1999. Memoria del Flamenco. Madrid: Alianza.

Guillamón Álvarez, J. 1981. Honor y honra en la España del siglo XVIII. Madrid: Universidad Complutense.

Hare, A. J. C. 2010. Wanderings in Spain. Londres: Dyson Press.

Lafuente Alcántara, E. 1865. Cancionero popular. Colección escogida de coplas y seguidillas. Tomo 2. Madrid: Carlos Bailly-Bailliere.

Lavaur, L. 2008. Teoría romántica del cante flamenco. Sevilla: Signatura Ediciones.

Lazo Díaz, A. 1974. "La política antigitana de los primeros Borbones en el Reino De Sevilla: Carmona". Archivo Hispalense LVII, 175: 1-33.

Lefranc, P. 2001, El cante jondo. Del territorio a los repertorios: tonás, siguiriyas y soleares. Sevilla: Universidad de Sevilla.

Lefranc, P. 2012a. "La génesis del martinete. Parte segunda: Consecuencias e implicaciones". Jondoweb.com http://www.jondoweb.com/contenido-la-genesis-de-martinete-ii-747.html. (Consultado 8-11-2012).

Lefranc, P. 2012b. "Entremés sobre el aparato llamado martinete", Triste y Azul. Flamencos cabales en la red. http://www.tristeyazul.com/hinvestigacion/Entremes_martinete_lefranc.html. (Consultado 8-11-2012).

Lefranc, P. 2012c. "Otro suplemento martinetero", Triste y Azul. Flamencos cabales en la red. http:// www.tristeyazul.com/hinvestigacion/Martinete_Pierre_Lefranc.html. (Consultado 8-11-2012).

Luna, J. C. de. 1989. Gitanos de la Bética. Cádiz: Universidad de Cádiz.

Luna, J. C. de. 2010. De cante grande y cante chico. Sevilla: Extramuros.

Machado y Álvarez, A. 1998. Cantes Flamencos. Barcelona: DVD ediciones, Los Cinco Elementos.

Mairena, A. 1976. Las confesiones de Antonio Mairena. Sevilla: Universidad de Sevilla.

Mandly, A. 2010. Los caminos del Flamenco. Etnografía, cultura y comunicación en Andalucía. Sevilla: Signatura Demos.

Marcos Álvarez, F. 1998. Gremios en Badajoz: Catálogo de maestros y aprendices (siglo XVII). Mérida: Editora Regional de Extremadura.

Martín Quirantes, A. 1995. "Gitanos repobladores: el fracaso de una integración en el siglo XVI", en Los gitanos en la historia y la cultura. Actas de un congreso: 91-101. Granada: Consejería de Trabajo y Asuntos Sociales de la Junta de Andalucía.

Más y Prat, B. 1925. La tierra de María Santísima. Madrid: Renacimiento.

Mayo, F. de Sales. 1870. El gitanismo, historia, costumbres y dialecto de los gitanos. Madrid: Librería de Victoriano Suárez.

Mejías Escassy, L. 1865. Los gitanos de la Caba o ya cayó el Ministerio. Pinto: Imprenta de G. Alhambra.

Molina, R. y Mairena, A. 1978. Mundo y formas del cante flamenco. Sevilla: Librería Al-Andalus.

Molina Fajardo, E. 1974. El flamenco en Granada. Teoría de sus orígenes e historia. Granada: Miguel Sánchez Editor.

Moncada, S. 1746. Restauración política de España y deseos públicos. Madrid: Juan de Zúñiga.

Núñez, F. 2008. Guía comentada de música y baile preflamencos (1750-1808). Barcelona: Ediciones Carena.

Pedrell, F. 2009. Diccionario Técnico de la música. Barcelona: Editorial Maxtor.

Pérez de Guzmán, T. 1982. Los gitanos herreros de Sevilla. Sevilla: Ayuntamiento de Sevilla.

Rodríguez Campomanes, P. 1774. Discurso sobre el fomento de la industria popular. Madrid: Imprenta de D. Antonio de Sancha.

Rodríguez Marín, F. 2005. Cantos populares españoles. Sevilla: Ediciones Espuela de Plata. 
Romero Ferrer, A. 1993. El género chico. Introducción al estudio del teatro corto fin de siglo (De sus incidencias gaditanas). Cádiz: Universidad de Cádiz.

Sánchez, Ma H. 1977. Los gitanos españoles. El período borbónico. Madrid: Castellote Editor.

Santamaría Conde, A. 1986. "Sobre la vida de los moriscos granadinos deportados en la villa de Albacete". Al-Basit. Revista de estudios albacetenses 18: 5-32.

Sanz Pérez, J. 1849. El Tío Caniyitas o El mundo nuevo de Cádiz. Cádiz: Imprenta, Librería y Litografía de la Revista Médica.

Schuchardt, H. 1990. Los cantes flamencos. Sevilla: Fundación Machado.

Steingress, G. 2006. Sociología del cante flamenco. Sevilla: Signatura Ediciones.

Steingress, G. 2007. «El trasfondo bizantino del cante flamenco. Lecciones del Encuentro entre el flamenco andaluz y el rebético greco-oriental (Granada, junio 2005)", en Flamenco Postmoderno: Entre tradición y heterodoxia. Un diagnóstico sociomusicológico. (Escritos 1989-2006): 305-347. Sevilla: Signatura Ediciones.

Suárez Ávila, L. 1994. "Bernardo del Carpio y los gitanos bajoandaluces", en Rebés, S. (coord.), Actes del Colloqui sobre cançó tradicional. Barcelona: Publicacions de l'Abadia de Montserrat.

Suárez Ávila, L. 2006. «Poética y tradición de los romances gitanos andaluces: 'El Lebrijano', un caso de fragmentismo y contaminación romancística". Culturas Populares, Revista electrónica 2: 225-268.

Suárez de Figueroa, C. 1629. Plaza universal de todas ciencias y artes. Perpiñán: Luys Roure Librero.

Tineo Rebolledo. J., 1900, "A Chipicalli" (La lengua gitana). Granada: Imprenta de F. Gómez de la Cruz.

Torre Molina, $\mathrm{M}^{\mathrm{a}} \mathrm{J}$. de la. 2003. Música y ceremonial en las fiestas reales de proclamación de España e Hispanoamérica (1746-1814). Tesis Doctoral. 3 vols. Granada.

Triana, F. el de. 1986. Arte y artistas flamencos. Madrid: Editoriales Andaluzas Unidas.

Vicente, G. 1843. Obras. Lisboa: Livraria europea de Baudry.

Zabaleta, J. de. 1652. Problemas de la filosofía natural, acompañados de consideraciones morales. Madrid.

Zayas, R. de. 2006. Los moriscos y el racismo de Estado. Creación, persecución y deportación (14991612). Almuzara: Sevilla.

Zoido Naranjo, A. 2009. La ilustración contra los gitanos. Antecedentes, Historia y consecuencias de la Prisión General. Sevilla: Signatura Ediciones.

Fecha de recepción: 12 de febrero de 2013

Fecha de aceptación: 9 de septiembre de 2013 